\title{
Anti-inflammatory activity of Anthemis tricolor Boiss
}

\author{
Serkan Demirkan¹, Özge Özçınar², Bijen Kıvçak ${ }^{2}$ \\ ${ }^{1}$ Department of Dermatology and Venerology, Faculty of Medicine, Kirikkale University, Kirikkale, Turkey \\ ${ }^{2}$ Department of Pharmacognosy, Faculty of Pharmacy, Ege University, İzmir, Turkey
}

Adv Dermatol Allergol 2019; XXXVI (6): 677-680

DOI: https://doi.org/10.5114/ada.2019.91417

\begin{abstract}
Introduction: Traditionally, Anthemis genus has been used for the treatment of gastrointestinal disorders, haemorrhoid and stomach ache in Europe. There are several in-vitro and in-vivo studies that showed the pharmacological properties of Anthemis species such as antibacterial, anti-inflammatory, antiedemic and hepatoprotective properties.

Aim: Our study referred to the model of inflammation formed in rats; we aimed to evaluate anti-inflammatory properties of $A$. tricolor extracts.

Material and methods: Five different extracts of $A$. tricolor were tested against the negative control and 2 different topical corticosteroids (betamethasone and hydrocortisone); $n$-hexane and sesquiterpene extracts of $A$. tricolor Bois showed significantly reduced erythema compared to the negative control.

Results: Only $n$-hexane and sesquiterpene extracts of A. tricolor have the anti-inflammatory effect.

Conclusions: This is the first report on anti-inflammatory activity of $A$. tricolor and we showed an anti-inflammatory effect of $n$-hexane and sesquiterpene extract of $A$. tricolor with UV erythema test as a_result, hence $A$. tricolor extracts can be used for the treatment of inflammatory skin diseases due to anti-inflammatory activity.
\end{abstract}

Key words: Anthemis tricolor, anti-inflammatory, $n$-hexane, sesquiterpene, minimal erythema dose.

\section{Introduction}

The Anthemis genus, belonging to the Asteraceae family, is composed of about 210 species [1]. In Cyprus there are 10 species belonging to the Anthemis genus and one of them is endemic Anthemis tricolor Boiss [2, 3]. Traditionally, the Anthemis genus has been used for the treatment of gastrointestinal disorders, haemorrhoid and stomach ache in Europe [4-7]. There are several in-vitro and in-vivo studies that showed the pharmacological properties of Anthemis species such as antibacterial [8, 9], anti-inflammatory [10, 11], antiproliferative [12] and antiprotozoal [13] properties. Our previous studies indicated the possible anti-inflammatory effect of $A$. tricolor $[10,11]$.

The most commonly used method to investigate the anti-inflammatory potential of topical dermatological preparations is the UV erythema test [14-17]. The preparations are applied to the skin in the form of occlusion with positive and negative controls. Regression power of erythema of the preparation is measured 24 and/or $48 \mathrm{~h}$ after UVB application $[14,15]$.

\section{Aim}

Our study used the model of inflammation formed in rats; we aimed to evaluate anti-inflammatory properties of $A$. tricolor extracts. The bioactivity and chemical composition studies of $A$. tricolor have so far been limited and there has been no report on anti-inflammatory activity.

\section{Material and methods}

In our study, 5 different extracts of $A$. tricolor were tested against the negative control and 2 different topical corticosteroids (betamethasone and hydrocortisone).

\section{Plant material}

The aerial part of $A$. tricolor Boiss was collected in March 2013 from the Kalkanlı region of North Cyprus. The material was identified by Özge Özçınar. A voucher specimen was deposited in the Herbarium of the Faculty of Pharmacy at Ege University, İzmir.

Address for correspondence: Serkan Demirkan MD, Department of Dermatology and Venerology, Faculty of Medicine, Kirikkale University, Yenisehir District, Tahsin Duru Avenue, No. 14, Yahsihan, Kirikkale, Turkey, phone: +90 5537717168 , fax: +90 3182444697 , e-mail: serkan.demirkan@yahoo.com.tr

Received: 22.02.2018, accepted: 11.07.2018. 


\section{Extraction of plant material}

$n$-Hexane, chloroform and methanol extracts were separately prepared from $150 \mathrm{~g}$ of the aerial parts of air-dried and powdered plant material by extracting on a shaker (room temperature/200 rpm) for $48 \mathrm{~h}$ (150 g of the plant material/1500 $\mathrm{ml}$ of the solvent). The solvents were then removed to dryness under reduced pressure. The yields of $n$-hexane, chloroform and methanol extracts were $0.38 \%, 1.42 \%$ and $6.4 \%$, respectively.

\section{Preparation of fatty acid extract}

The oil extraction of the air dried and powdered aerial parts (10 g) of $A$. tricolor was carried out at $60^{\circ} \mathrm{C}$ for $6 \mathrm{~h}$ by Soxhlet extractor, using petroleum ether as a solvent. The solvent was evaporated by a rotary evaporator. The fatty acids were esterified into methyl esters by saponification with $0.5 \mathrm{~N}$ methanolic $\mathrm{NaOH}$ and transesterified with 14\% BF3 (v/v) in methanol [10].

\section{Total sesquiterpene lactone extract}

Air-dried plant material (40 g) was extracted at room temperature with petroleum ether-Et $\mathrm{O}$ (peroxide-free)$\mathrm{MeOH}(1: 1: 1 \mathrm{v} / \mathrm{v})$ and evaporated under vacuum to yield a crude extract. This extract was dissolved in a mixture of cyclohexane-Et $\mathrm{O}$ (peroxide-free)-MeOH (1:1:1 v/v), then brine was added and it was extracted with EtOAc. The organic phase was concentrated under vacuum to dryness and yielded a lipophilic residue (1.2\%).

\section{Preparation of test specimens for bioassay}

All extracts were suspended in a suspension of $0.5 \%$ sodium carboxymethyl cellulose (CMC) in distilled water.

\section{Animals}

Forty male Albino Wistar rats weighing 450-500 mg were included in the prospective, randomized, double blind study. The rats were kept under appropriate conditions for moisture and temperature $\left(24 \pm 2^{\circ} \mathrm{C}\right)$. The rats had unlimited access to water and food. The rats were shaved with a razor blade and foam. All study designs and methods were approved by the Kırıkkale University Animal Ethics Committee.

\section{Anti-inflammatory activity model}

Five fluorescent Philips PLL33W (Philips GmbH, Hamburg, Germany) lamps with the highest wavelength of $310 \mathrm{~nm}$ placed on a UV $181 \mathrm{BL}$ (Waldmann GmbH, VS-Schwenningen, Germany) phototherapy device were used for irradiation. UV-B was applied at a gradual incremental dose $\left(0.2 \mathrm{~mJ} / \mathrm{cm}^{2}\right)$ to detect a minimal erythema dose (MED) to the shaved abdominal area of the rat. For the Wistar albino rat, MED was found to be $1 \mathrm{~mJ} / \mathrm{cm}^{2}, 1.5$ fold MED; each $1 \mathrm{~cm}^{2}$ area was treated with $1.5 \mathrm{~mJ} / \mathrm{cm}^{2}$ UVB (Figure 1). The erythema in these areas was mea- sured photometrically using Mexameter (t1) [14]. Material to be tested was administered by a blind applicator in the form of occlusion in a volume of $50 \mu \mathrm{l}$ to each test site in accordance with the randomization schedule. Patches were removed $47 \mathrm{~h}$ after applying the material and an $1 \mathrm{~h}$ before evaluating the test areas to prevent false positivity against the patches. Afterwards, the erythemas of all test areas were measured (t2) and photometric documentation was done.

\section{Statistical analysis}

All data were recorded and compared using two separate databases. Anova and Mann Whitney $U$ tests were applied using the SPSS program and statistical analyses and comparisons were made.

\section{Results}

$n$-Hexane and the total sesquiterpene lactone extract of $A$. tricolor Boiss significantly reduced erythema compared to the negative control $(p<0.001)$. The erythema in the area where the $n$-hexane extract was used was significantly lower than that of the other extracts of A. tricolor Boiss $(p<0.001)$. The erythema in the area where the $n$-hexane extract was used was significantly higher than in the areas using betamethasone 17-valerate and hydrocortisone acetate $(p<0.001)$. Significantly more erythema was found in the areas where the sesquiterpene extract was used than in the area where betamethasone 17-valerate and hydrocortisone acetate were used ( $p<0.001)$, but there was significantly less erythema than methanol and fatty acid extracts $(p<0.001)$. There was no significant difference between the area where the sesquiterpene extract was used and the area where the chloroform extract was used $(p=0.267)$. There was no difference in the area between the negative control used area and the areas using methanol, chloroform, fatty acid extract in terms of erythema $(p>0.05)$. There was no significant difference between betamethasone 17-valerate and hydrocortisone acetate in terms of UVB-induced erythema $(p=0.223)$. Erythema in areas using betamethasone 17-valerate and hydrocortisone acetate was significantly lower than that in areas using the negative control, chloroform, $n$-hexane, ethanol, fatty acid extracts ( $p<$ 0.001). There was no irritation (erythema) due to patches in the non-irradiated test areas (Table 1).

\section{Discussion}

The UV erythema test is used to measure the antiinflammatory effect of topically applied substances [14, $15,18]$. It had been first applied to the rats for comparison with the foot oedema test [19]. The UV erythema test should be done with at least 40 samples and the applied UVB should be 1.5-fold MED [14]. It is useful to add cor- 
ticosteroids such as betamethasone and hydrocortisone as a control substance to evaluate anti-inflammatory activity [14]. In a study of acute and chronic inflammatory models investigating the anti-inflammatory effect of extracts in rats, the extract of $A$. aciphylla var. aciphylla Boiss was systemically administered; it is reported that this plant is effective in both acute and chronic inflammatory processes [11]. The results of our study showed that only $n$-hexane and sesquiterpene extracts of $A$. tricolor have the anti-inflammatory effect. The effects of topically applied herbal extracts differ between themselves due to the differences in the constituents of extracts, tissue penetration and different properties in the physicochemical reactions.
The anti-inflammatory effect of $\mathrm{n}$-hexane and sesquiterpene extract of $A$. tricolor Boiss is lower than that of betamethasone 17-valerate and hydrocortisone acetate. Corticosteroids are one of the highest anti-inflammatory agents. However, when considering the side effect profile of topical corticosteroids; Boiss' hexane and sesquiterpene extract of $A$. tricolor may be a good alternative. Although the UV erythema test is known as the optimal anti-inflammatory model, the anti-inflammatory properties of $A$. tricolor can be investigated by creating other inflammatory models.

A. tricolor can be investigated by in-vivo tests by establishing a similar model of anti-inflammatory activity in humans to assess anti-inflammatory activity.
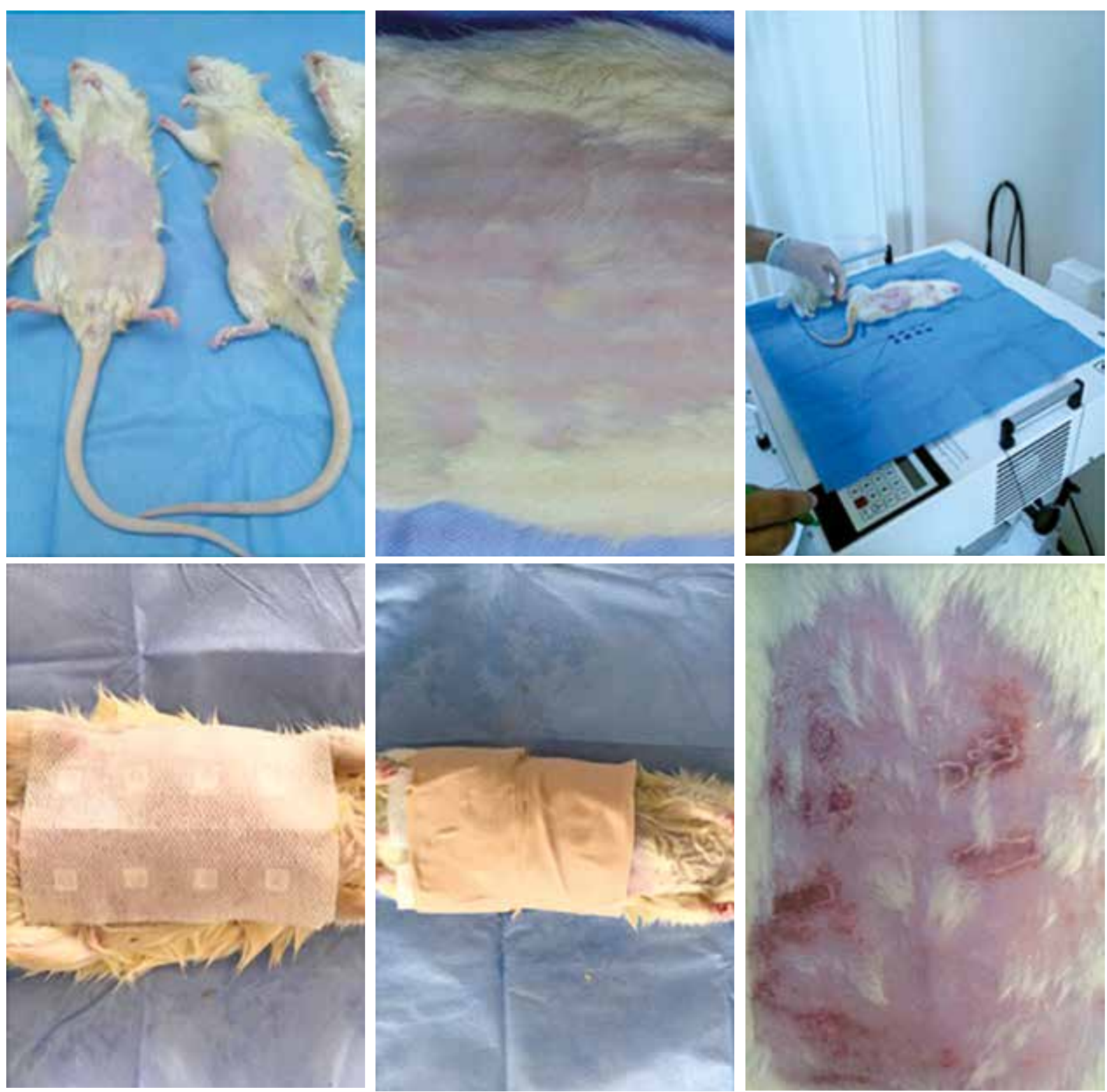

Figure 1. Procedure for measurement of anti-inflammatory activity 
Table 1. Effects of the preparations on the erythema occurring in 1.5-fold MED UVB-applied areas

\begin{tabular}{lccccc}
\hline Preparation & Mean & SD & Median & Min. & Max. \\
\hline Hydrocortisone acetate & 25.80 & 1.99 & 25.50 & 21 & 29 \\
\hline Betamethasone 17-valerate & 23.78 & 2.13 & 24.00 & 20 & 28 \\
\hline Placebo & 46.58 & 2.17 & 47.00 & 41 & 49 \\
\hline Hexane extract & 32.83 & 2.95 & 32.00 & 30 & 44 \\
\hline Sesquiterpene extract & 42.43 & 4.74 & 43.00 & 33 & 49 \\
\hline Chloroform extract & 44.38 & 2.62 & 45.00 & 40 & 49 \\
\hline Methanol extract & 46.38 & 3.53 & 47.00 & 41 & 56 \\
\hline Fatty acid extract & 48.45 & 3.76 & 50.50 & 41 & 57 \\
\hline
\end{tabular}

\section{Conclusions}

This is the first report on anti-inflammatory activity of A. tricolor and we showed the anti-inflammatory effect of $n$-hexane and sesquiterpene extract of $A$. tricolor with UV erythema test as a result, $A$. tricolor Boiss extracts can be used for the treatment of inflammatory skin diseases due to anti-inflammatory activity. Further studies are warranted to investigate the phytochemical composition of these extracts.

\section{Conflict of interest}

The authors declare no conflict of interest.

\section{References}

1. Bremer K. Asteraceae, Cladistics and Classification. Timber Press, Portland, Oregon 1994; 435-78.

2. Meikle RD. Flora of Cyprus. Vol. 2. Kew: Bentham-Moxon Trustand Royal Botanic Gardens 1985.

3. Karaalp C, Erel SB, Nalbantsoy A, et al. The essential oil composition of aerial parts of Anthemis tricolor Boiss. from Cyprus. Nat Prod Res 2014; 28: 488-91.

4. Baytop T. Therapy with Medicinal Plants in Turkey (Past and Present). Istanbul University, Istanbul 1984; 305.

5. Honda G, Yesilada E, Tabata M, et al. Traditional medicine in Turkey. VI. Folk medicine in west Anatolia: Afyon, Kütahya, Denizli, Muğla, Aydin provinces. J Ethnopharmacol 1996; 53: 75-87.

6. Gürhan G, Ezer N. Plants which have been used for haemorrhoids in folk medicine-I. Hacettepe Univ J Fac Pharm 2004; 24: 37-55.

7. Karcı E, Gürbüz I, Akaydın G, Günbatan T. Folk medicines of Bafra (Samsun-Turkey). Turk J Biochem 2017; 42: 381-99.

8. Gulsoy Toplan G, Tuysuz M, Mat A, Sariyar G. Antibacterial activity of Anthemis tricolor Boiss from Cyprus. PMIO 2017; 4 (Suppl 1): S1-202.

9. Riccobono L, Maggio A, Bruno M, et al. Natural Product Research Chemical composition and antimicrobial activity of the essential oils of some species of Anthemis sect. Anthemis (Asteraceae) from Sicily. Nat Product Res 2017; 31: 2759-67.

10. Gönenç TM, Akkol EK, Süntar I, et al Fatty acid composition and preclinical resarches on Anthemis wiedemanniana
Fisch. \& Mey.: discovery of a new anti-inflammatory agent. Pharmacogn Mag 2014; 10: 53.

11. Baltacı S, Kolatan HE, Yilmaz O, Kivcak B. Anti-inflammatory activity of Anthemis aciphylla var. aciphylla Boiss. Turk J Biol 2011; 35: 757-62.

12. Réthy B, Csupor-Löffler B, Zupkó I, et al. Antiproliferative activity of Hungarian Asteraceae species against human cancer cell lines. Part I. Phytother Res 2007; 21: 1200-8.

13. De Mieri M, Monteleone G, Ismajili I, et al. Antiprotozoal activity-based profiling of a dichloromethane extract from Anthemis nobilis flowers. J Nat Prod 2017; 80: 459-70.

14. Jocher A, Kessler S, Hornstein S, et al. The UV erythema test as a model to investigate the anti-inflammatory potency of topical preparations - reevaluation and optimization of the method. Skin Pharmacol Physiol 2005; 18: 234-40.

15. Juhlin L, Shroot B. Effect of drugs on the early and late phase UV erythema. Acta Derm Venerol 1992; 72: 22-3.

16. Takiwaki H, Shirai S, Kohno H, et al. The degrees of UV-B induced erythema and pigmentation correlate linearly and are reduced in a paralel manner by topical anti-inflammatory agents. J Invest Dermatol 1994; 103: 642-6.

17. Hughes-Formella BJ, Bohnsack K, Rippke F, et al. Anti-inflammatory effect of hamamelislotion in a UV-B erythema test. Dermatology 1998; 196: 316-22.

18. Raake W. Comparison of the anti phlogistic effect of mucopolysaccharide-polysulfate ointments with heparin-containing ointments in the UV erythema test. Drug Res 1984; 34: 449-51.

19. Jahn U, Wagner-Jauregg T. Comparative activity of acidantiphlogistics in the bradykinin, UV erythema and rat foot edema test (in German). Arzneimittelforschung 1974; 24: 494-9. 